\title{
Rancang Bangun Pembangkit Listrik Menggunakan Solenoida Dengan Pemanfaatan Fluks Magnet
}

\author{
Yusdi Kurniawan, Zulkifli \\ Teknik Listrik, Politeknik Negeri Bengkalis \\ Jl.Bathin Alam, Sungai Alam, Bengkalis, Riau,Indonesia \\ e-mail: yusdikurnia23@gmail.com
}

\begin{abstract}
Abstrak - Solenoida adalah kumparan yang terbuat dari kabel panjang yang dililitkan secara rapat, berdasarkan hukum faraday yang berbunyi apabila terjadi perubahan fluks maka akan ada gaya gerak listrik yang sebanding dengan laju perubahan fluks. perubahan fluks terjadi apabila ada magnet yang di keluar masukkan ke dalam solenoida, dengan menggunakan led hijau sebagai indikator didapatkan hasil yang bervariasi sesuai dengan RPM penggerak yang digunakan. solenoida yang digunakan sebanyak 2 buah dengan masing-masing 3100 lilitandan menggunakan magnet neodymium. untuk RPM 200 tegangan yang didapatkan sebesar $0,5 \mathrm{~V}$, teganga $1 \mathrm{~V}$ dengan arus $0,6 \mathrm{~mA}$ dari RPM 400, RPM 600 didapatkan teganga 1,6 V dengan arus 3,2 mA, RPM 800 didapatkan tegangan sebesar 2,2 V dengan arus sebesar 6,6 mA.
\end{abstract}

Kata kunci : Solenoida, Fluks Magnet, Tegangan

Abstract - Solenoids are coils made of long wires that are tightly wrapped, based on faraday law that sounds when there is a change in flux, there will be an electric force proportional to the rate of change in flux. changes in flux occur when there is a magnet that is inserted into the solenoid. by using a green led as an indicator the results vary according to the drive RPM used. 2 solenoids were used with 3100 each and using neodymium magnets. for $200 \mathrm{RPM}$ the voltage obtained is $0.5 \mathrm{~V}$, the voltage is $1 \mathrm{~V}$ with a current of $0.6 \mathrm{~mA}$ from RPM 400, RPM 600 is obtained with a voltage of $1.6 \mathrm{~V}$ with a current of $3.2 \mathrm{~mA}$, $R P M 800$ is obtained with a voltage of $2.2 \mathrm{~V}$ with current of $6.6 \mathrm{~mA}$.

Keywords : $\quad$ Solenoids, Magnetic Flux, Voltage

\section{PENDAHULUAN}

Listrik merupakan elemen penting dalam kehidupan manusia, aktivitas manusia setiap hari memerlukan listrik. Pengembangan listrik perlu ditingkatkan mengingat energi listrik saat ini masih banyak menggunakan bahan bakar fosil yang tidak dapat diperbaharui. Masalah yang dihadapi oleh penyedia energi listrik saat ini yaitu belum meratanya penyediaan energi listrik untuk masyarakat pedalaman, hal ini dikarenakan wilayah Indonesia yang sangat luas. Distribusi energi listrik akan mudah dijangkau pada tempat yang dekat dengan pembangkit atau tempat-tempat umum. Namun pendistribusian akan sulit jika lokasi konsumen yang jauh sehingga tidak mudah dijangkau, seperti pulau-pulau kecil dan pedalaman. Berdasarkan permasalahan yang ada, maka perlu dilakukan pengembangan energi listrik yang diperlukan untuk mengatasi masalah krisis energi listrik, salah satunya yaitu mengembangkan pembangkit energi listrik yang memanfaatkan medan magnet yang bergerak di dalam solenoid. Pemanfaatan medan magnet dan solenoid dalam bidang kelistrikan saat ini belum terlalu dikembangkan, karena masih dalam kapasitas kecil. Perubahan medan magnet di sekitar solenoid dapat menimbulkan arus listrik, bukan hanya medan magnet, fenomena perubahan medan magnet yang menghasilkan arus listrik dinamakan induksi elektromagnetik. Penelitian ini merupakan langkah awal yang bertujuan untuk mempelajari pembangkitan gaya magnetik pada formasi konduktor berbentuk kumparan dalam medan magnet yang bersumber dari magnet permanen. Penggunaan konduktor berbentuk kumparan dan magnet permanen sebagai pembangkit medan magnet diharapkan mampu menghasilkan gaya magnetik yang besar dan stabil sebagai dasar dalam mengembangkan prototipe pembangkit listrik memanfaatkan medan magnet yang bergerak di dalam solenoid.

\section{TINJAUAN PUSTAKA}

Solenoida

Magnet yang melewati kumparan akan menimbulkan arus listrik, dan jika kumparan dialiri arus listrik maka akan menimbulkan medan magnet, dengan menggerak-gerakan magnet dalam kumparan maka akan menimbulkan arus listrik, arus listrik yang timbul dari hasil gerakan magnet disebut arus induksi. Arah arus induksi adalah bolak balik. Bila jumlah garis gaya magnet yang masuk dalam kumparan berubah, maka pada ujung ujung kumparan timbul gaya gerak listrik (GGL). Semakin cepat perubahan gaya magnet yang masuk kedalam kumparan, maka 
semakin besar pula GGL induksi yang timbul, dan makin banyak lilitan kawat pada kumparan, maka GGL induksi juga semakin besar. Jumlah garis gaya magnet yang masuk kedalam kumparan dapat berubah dengan cara berikut [1].

a. Menggerakkan magnet batang keluar masuk kumparan.

b. Memutar magnet dekat kumparan.

c. Mendekatkan kumparan pada kutub magnet.

d. Memutus-mutus arus primer untuk menginduksi arus sekunder pada kumparan lain.

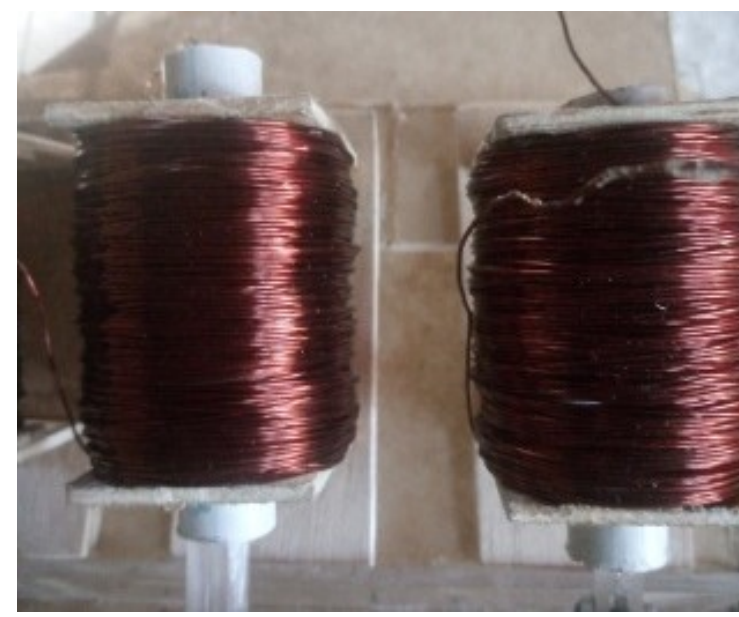

Gambar 1. Solenoida

\section{Magnet Neodymium}

Karakteristik magnet yang dimiliki $\mathrm{NdFeB}$ lebih baik bila dibandingkan dengan magnet permanen lainnya, seperti Ferit, Alnico dan Samarium Cobalt. BH yang dimiliki dapat berkisar antara 30 MGOe sampai dengan 52 MGOe. Karena memiliki karakteristik magnet yang tinggi, maka dalam aplikasinya magnet $\mathrm{NdFeB}$ memiliki dimensi dan volume yang kecil. Dalam beberapa aplikasi, magnet ini juga dapat menggantikan penggunaan magnet Samarium Cobalt, khususnya penggunaan pada suhu kurang dari $80^{\circ} \mathrm{C}$. Aplikasi magnet $\mathrm{NdFeB}$ cukup banyak, seperti pada peralatan elektronik, motor listrik/generator, sensor/tranduser, industri otomotif, industri petrokimia dan produk peralatan kesehatan. Keunggulan lain yang dimiliki oleh magnet $\mathrm{NdFeB}$ adalah memiliki harga yang lebih murah dibandingkan dengan magnet yang lain. Tetapi kekurangannya adalah tidak dapat diaplikasikan pada suhu tinggi, yaitu hanya maksimum berkisar sampai $200^{\circ} \mathrm{C}[2]$

Magnet neodymium, merupakan magnet tetap yang sangat kuat. Magnet neodymium (juga dikenal sebagai $\mathrm{NdFeB}$, NIB, atau magnet $\mathrm{Neo}$ ), merupakan sejenis magnet tanahj arang, terbuat dari campuran logam neodymium. Secara khusus, korosi sekecil apapun dapat menyebabkan kerusakan magnet sinter. Masalah ini dibahas dalam banyak produk komersial dengan menyediakan lapisan pelindung. Pelapisan nikel atau dua pelapisan tembaga berlapis nikel digunakan sebagai metode standar, meski pun pelapisan dengan logam lainnya atau polimer dan lapisan pelindung pernis juga digunakan. Magnet neodymium dapat dilihat pada gambar berikut.

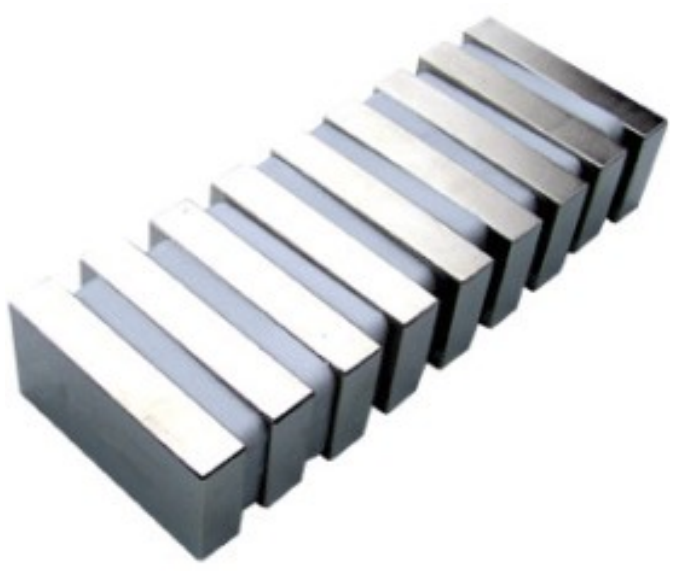

Gambar 2. Magnet Neodymium

Medan Magnet

Medan magnet adalah ruang di sekitar magnet yang memiliki gaya magnetik, gaya magnet yang timbul berasal dari dua kutub selatan (S) dan utara (U). Muatan yang bergerak atau arus listrik dapat menimbulkan medan magnet di ruang sekitarnya. Kutub berbeda saling menarik dan menolak dapat dilihat pada Gambar berikut.

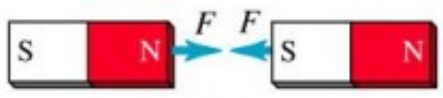

(a)

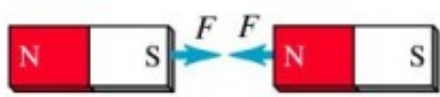

(b)
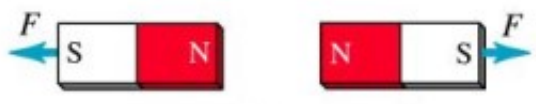

(c)
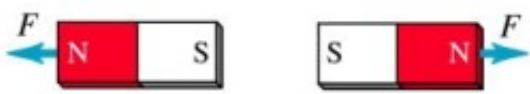

(d)

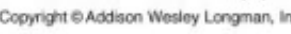

Gambar 3 sifat dari kutub pada magnet

Ketika dua magnet didekatkan satu sama lain seperti pada Gambar 2.1, masing-masing akan memberikan gaya kepada yang lain, gaya ini dapat berupa gaya tarik menarik atau tolak menolak. Jika kutub yang sejenis didekatkan maka dapat dirasakan bahwa magnet tersebut susah untuk disatukan, 
sehingga semakin besar gaya yang diberikan untuk menyatukan kedua magnet, maka semakin kedua magnet tersebut memberikan gaya yang lebih besar untuk memisahkan diri. Namun jika kutub kutub tidak sejenis maka magnet tersebut memberikan gaya tarik menarik satu sama lain, sehingga tidak membutuhkan gaya yang besar untuk menyatukan magnet tersebut. Kuat medan magnet dapat dilihat dengan Persamaan berikut ini.

$$
B=\frac{\mu_{0} \cdot i \cdot N}{l}=\mu_{0} \cdot i \cdot N \ldots \ldots \ldots \ldots \ldots
$$

Dimana:

$$
\begin{aligned}
& 1 \text { = panjang solenoida }(\mathrm{m}) \\
& \mathrm{i}=\text { arus pada solenoida }(\mathrm{A}) \\
& \mathrm{N}=\text { banyaknya lilitan } \\
& \mathrm{n}=\text { banyaknya lilitan persatuan panjang }(\mathrm{N} / 1)
\end{aligned}
$$

Ruang di sekitar suatu magnet dimana benda lain yang mudah dipengaruhi magnet akan mengalami gaya magnetic jika diletakkan dalam ruang tersebut didefenisikan sebagai medan magnet atau dapat dikatakan juga sebagai fluks magnetik. Hal ini dapat dibuktikan dengan menaburi serbuk besi pada magnet, maka serbuk besi akan ditarik oleh kutub magnet dan membentuk pola garis, disebut garis gaya magnet. Persamaan untuk fluks magnetic dapat dilihat pada persamaan berikut ini.

$$
\phi=B \cdot A
$$

Dimana:

$\Phi$ :adalahfluks magnet $\left(\mathrm{Wb} / \mathrm{m}^{2}\right.$ atau $\left.\mathrm{T}\right)$

A :adalahluaspermukaan $\left(\mathrm{m}^{2}\right)$

$\mathrm{B}$ :adalahkuatmedanmagnet (Wbatau T)

Hukum Faraday

Konsep gaya gerak listrik dikemukakan oleh Michael Faraday, yang melakukan penelitian unruk menentukan faktor menentukan faktor yang memengaruhi besarnya GGL yang diinduksi. Faraday menemukan bahwa induksi sangat bergantung pada waktu, yaitu semakin cepat terjadinya perubahan medan magnetik, GGL yang diinduksi semakin besar. Hasil pengamatan Faraday menemukan bahwa [1].

a. Pada saat magnet digerakkan (keluar-masuk) dalam kumparan jarum pada galvanometer menyimpang.

b. Penyimpangan jarum galvanometer menunjukkan bahwa di dalam kumparan mengalir arus listrik. Arus listrik seperti ini disebut arus induksi.

c. Arus listrik timbul karena pada ujung-ujung kumparan timbul beda potensial. Beda potensial ini disebut gaya gerak listrik induksi (GGL induksi). d. Timbulnya GGL induksi pada ujung-ujung kumparan disebabkan karena adanya perubahan garis gaya magnetik yang memotong kumparan.

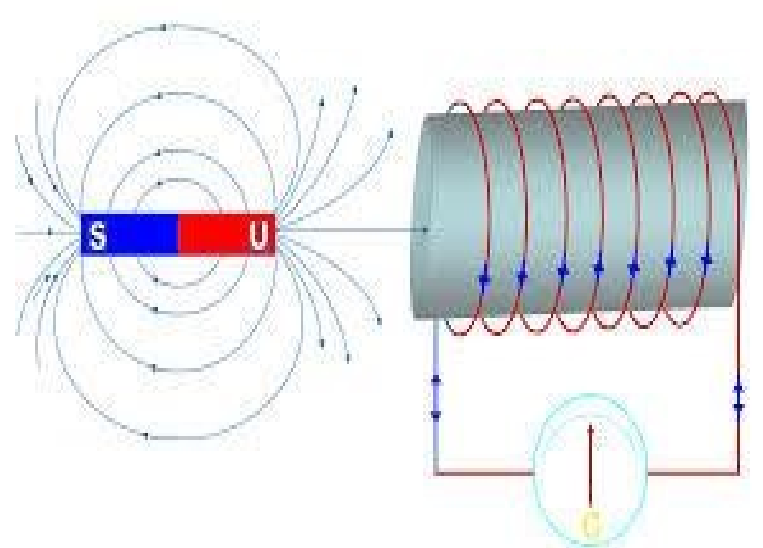

Gambar 4 Magnet Akan Bergerak Masuk Kumparan

Hasil tersebut membuat Faraday menyatakan bahwa "Apabila terjadi perubahan fluks dalam suatu solenoid maka akan dihasilkan gaya gerak listrik yang sebanding dengan laju perubahan fluks", dinyatakan dengan Persamaan berikut ini.

$$
\varepsilon=-N \frac{\Delta \emptyset}{\Delta t}
$$

Dimana :

$$
\begin{aligned}
& \varepsilon=\text { GGL induksi (volt) } \\
& \mathrm{N}=\text { banyaknyalilitankumparan } \\
& \Delta \mathrm{F}=\text { perubahanfluksmagnetik (weber) } \\
& \Delta \mathrm{t}=\text { selangwaktu (s) }
\end{aligned}
$$

Penyearah

Penyearah adalah bagian dari power supply yang berfungsi untuk mengubah sinyal tegangan AC menjadi tegangan DC. Komponen utama dalam penyearah gelombang adalah dioda yang dikonfigurasikan secara forward bias. Filter diperlukan untuk memperkecil tegangan ripple, sehingga dapat diperoleh tegangan keluaran yang lebih rata, filter diperlukan karena rangkaian rangkaian elektronik memerlukan tegangan DC yang tetap.

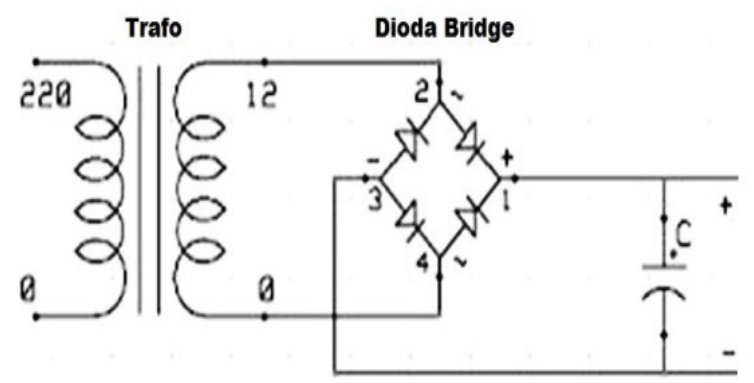

Gambar 5 Penyearah Satu Fasa 


\section{Prinsip kerja}

Dalam sistem pembangkit memanfaatkan solenoid terdapat peralatan-peralatan penting yang sangat berperan dalam sistem kerja pembangkit mulai dari awal proses hingga energi listrik yang dihasilkan, diantaranya sistem penggerak utama yaitu motor DC, sistem transmisi penggerak magnet, dan sistem induksi untuk penghasil energi listrik.

Pada sistem kerja pembangkit menggunakan solenoid, untuk mendapatkan pergerakkan magnet di dalam solenoid, sumber utama yaitu motor DC, motor akan menggerakkan sistem transmisi yang terhubung dengan piston magnet, kemudian piston magnet akan menginduksi solenoida, dari induksi medan magnet di dalam solenoid itu maka akan menghasilkan tegangan listrik. Tegangan listrik yang keluar dari solenoid adalah AC. Output dari solenoid masuk kedalam penyearah untuk merubah tegangan AC menjadi DC, sebagai indicator maka beban yang digunakan adalah lampu LED.

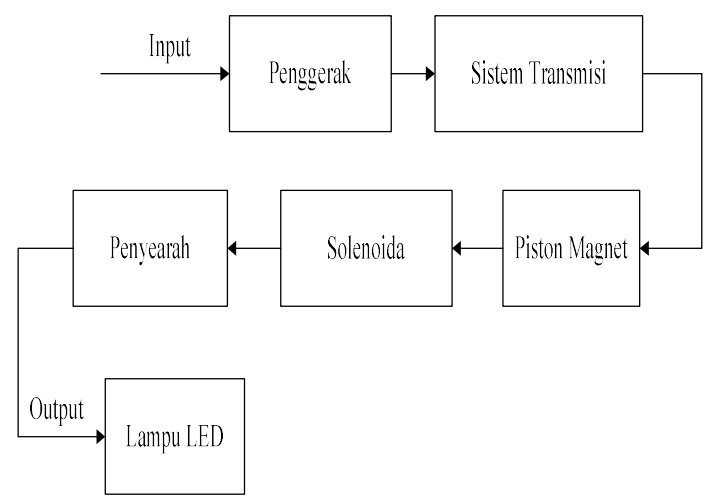

Gambar 6 Blok Diagram Alat

\section{Metode}

Metode yang dilakukan dalam penelitian ini adalah dimulai dari merancang solenoid, merancang sistem transmisi, pengambilan data dan menganalisa.

\section{Merancang Solenoida}

Solenoida terdiri dari2 buah sebagai penghasil energi listrik. Solenoida diletakkan disamping sistem transmisi yang berguna untuk mempermudah pergerakan pada sistem transmisi. Ukuran diameter penampang solenoid yaitu $1,8 \mathrm{~cm}$, panjang penampang solenoid yaitu $5 \mathrm{~cm}$, jumlah lilitan setiap solenoida masing masing sebanyak 3100 lilitan.

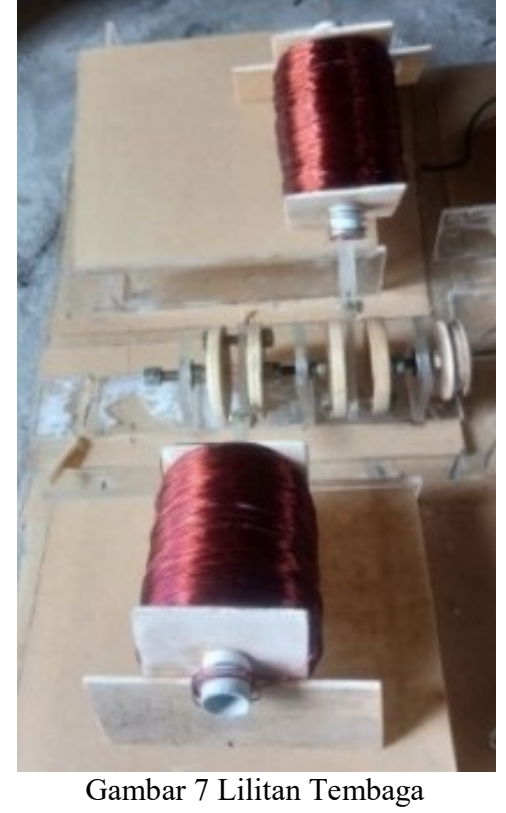

\section{Merancang Sistem Transmisi}

Sistem transmisi terdiri dari 2 buah tangan penggerak yang terhubung satu dengan yang lainnya. Ukuran diameter masing-masing lingkaran sistem transmisi yaitu $5 \mathrm{~cm}$.

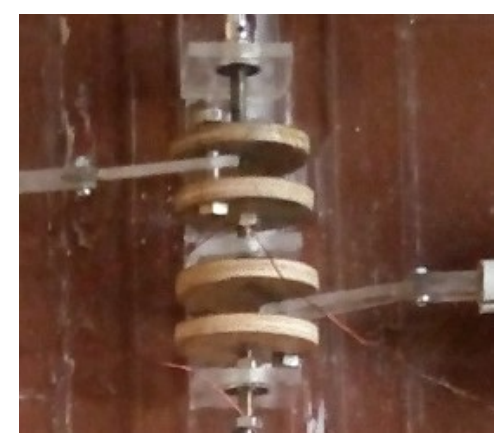

Gambar 8 Sistem Transmisi

Rancangan pengukuran yang dilakukan yaitu dengan mengukur langsung pada input dan output keluaran dari solenoida, ada beberapa kriteria yang di ambil berupa:

1. Mengukur tegangan DC dan arus DC yang keluar pada penyearah.

2. Mengukur RPM penggerak

Menganalisa kuat medan magnet yang timbul didalam solenoida. 


\section{HASIL DAN PEMBAHASAN}

Hasil dari pengukuran ini berupa tegangan dan arus dari RPM yang bervariasi, penelitian ini menggunakan beban berupa lampu LED hijau dengan tegangan kerja sebesar 2,6 V.

Tabel 1. Pengukuran tegangan dan arus keluaran dari penyearah.

\begin{tabular}{|c|c|c|c|}
\hline RPM & VDC & IDC & Keterangan LED \\
\hline $\mathbf{2 0 0}$ & $0,5 \mathrm{~V}$ & - & Belum menyala \\
\hline $\mathbf{4 0 0}$ & $1 \mathrm{~V}$ & $0,6 \mathrm{~mA}$ & Redup \\
\hline $\mathbf{6 0 0}$ & $1,6 \mathrm{~V}$ & $3,2 \mathrm{~mA}$ & Terang \\
\hline $\mathbf{8 0 0}$ & $2,2 \mathrm{~V}$ & $6,6 \mathrm{~mA}$ & Sangat terang \\
\hline
\end{tabular}

Dalam penelitian ini, jika melihat dari hasil pengukuran diatas dengan berbagai macam variasi putaran maka diikuti dengan hasil yang berbeda. Hal ini menunjukkan bahwa tegangan berbanding lurus dengan kecepatan putaran penggerak. Dari data yang di dapatkan diatas maka dapat dianalisa kuat medan magnet dan fluks magnet.

\section{Analisa kuat medan magnet}

Dengan data arus listrik yang didapat maka dapat dilakukan analisa menggunakan rumus kuat medan magnet $B=\frac{\mu_{0} \cdot i \cdot N}{l}$

Tabel 2. Perbandingan arus listrik dan medan magnet

\begin{tabular}{cc}
\hline Arus Listrik & Medan Magnet (B) \\
\hline $\mathbf{0 , 6} \mathbf{~ m A}$ & $5,48 \cdot 10^{-5}$ \\
$\mathbf{3 , 2} \mathbf{~ m A}$ & $29,2 \cdot 10^{-4}$ \\
$\mathbf{6 , 6} \mathbf{~ m A}$ & $6,03 \cdot 10^{-4}$ \\
\hline
\end{tabular}

2. Analisa fluks magnet

Untuk menganalisa fluks magnet sebelum itu harus diketahui luas penampang solenoida, luas penampang solenoida dengan diameter $0,018 \mathrm{~m}$ adalah $0,028 \mathrm{~m}^{2}$, dapat dilakukan analisa dengan menggunakan rumus fluks magnet $\phi=B \cdot A$

Tabel 3. Perbandingan arus listrik, medan magnet dan fluks magnet

\begin{tabular}{ccc}
\hline Arus Listrik & Medan Magnet $(B)$ & Fluks Magnet $(\phi)$ \\
\hline $\mathbf{0 , 6} \mathbf{~ m A}$ & $5,48 \cdot 10^{-5} \mathrm{~T}$ & $0,15 \cdot 10^{-5} \mathrm{~Wb} / \mathrm{m}^{2}$ \\
\hline $\mathbf{3 , 2} \mathbf{~ m A}$ & $29,2 \cdot 10^{-4} \mathrm{~T}$ & $0,081 \cdot 10^{-4} \mathrm{~Wb} / \mathrm{m}^{2}$ \\
\hline $\mathbf{6 , 6} \mathbf{~ m A}$ & $6,03 \cdot 10^{-4} \mathrm{~T}$ & $0,16 \cdot 10^{-4} \mathrm{~Wb} / \mathrm{m}^{2}$ \\
\hline
\end{tabular}

Tabel 4. Perbandingan RPM, tegangan, arus listrik dan fluks magnet

\begin{tabular}{|c|c|c|c|}
\hline RPM & Tegangan & Arus Listrik & Fluks Magnet \\
\hline 200 & $0,5 \mathrm{~V}$ & - & - \\
\hline 400 & $1 \mathrm{~V}$ & $0,6 \mathrm{~mA}$ & $0,15 \cdot 10^{-5} \mathrm{~Wb} / \mathrm{m}^{2}$ \\
\hline 600 & $1,6 \mathrm{~V}$ & $3,2 \mathrm{~mA}$ & $0,081 \cdot 10^{-4} \mathrm{~Wb} / \mathrm{m}^{2}$ \\
\hline 800 & $2,2 \mathrm{~V}$ & $6,6 \mathrm{~mA}$ & $0,16 \cdot 10^{-4} \mathrm{~Wb} / \mathrm{m}^{2}$ \\
\hline
\end{tabular}

\section{KESIMPULAN}

Dari hasil penelitian yang telah dilakukan dapat disimpulkan bahwa Pengaruh jumlah lilitan berbanding lurus dengan tegangan keluaran yang dihasilkan, semakin banyak jumlah lilitan maka tegangan keluar juga semakin besar. Kecepatan magnet yang bergerak juga berbanding lurus dengan tegangan keluaran, semakin cepat magnet bergerak maka semakin besar tegangan keluaran yang dihasilkan.

Kuat medan magnet juga berbanding lurus dengan tegangan dan arus keluaran yang dihasilkan, semakin besar medan magnet maka semakin besar keluaran yang dihasilkan. Semakin besar luas penampang solenoida maka semakin besar juga tegangan keluarannya. Panjang solenoida berbanding terbalik dengan kuat medan magnet yang dihasilkan, semakin pendek panjang solenoida maka semakin besar medan magnet yang dihasilkan.

Untuk penelitian selanjutnya dapat dilakukan dengan menggunakan penggerak yang bersumber dari angin, sehingga memang benar benar menggunakan energi terbaharukan.

\section{DAFTAR PUSTAKA}

[1] Ramlawati., Hamka, L., Saenab, S., danYunus, S. R. (2017) Mata PelajaranIpa Bab X KelistrikandanKemagnetan,KementerianPendidi kan Dan Kebudayaan, Jakarta.

[2] Irasari, P., dan Idayanti, N. (2007) Aplikasi Magnet Permanen Bafe12 O Dan Ndfeb Pada Generator Magnet Permanen KecepatanRendah Skala Kecil, Jurnal Sains Materi Indonesia, Vol. $11,38-41$.

[3] Setiadi, M. F., Sarwoko, M., dan Kurniawan, E. (2015) Pemanfaatan Fluks Magnetik Sebagai Sumber Pembangkit Tenaga Listrik Dengan Menggunakan Solenoida, Vol. 2, 7011-7018.

[4] Mayur, F., Jeetkumar, M., Preshitkumar, P., Sunny, P., dan Shah, P. (2017) "Solenoid Engine."Sieicon International Conference, Vadodara, Va. 1-7. 